\title{
Desdobramentos da Política Nacional de Educação Especial na Perspectiva da Educação Inclusiva em Políticas Locais
}

\author{
Neusete Machado Rigo ${ }^{1}$
}

\begin{abstract}
Resumo
Esse artigo tem por objetivo apresentar os impactos que a Política Nacional da Educação Especial na Perspectiva da Educação Inclusiva/2008 estão provocando nas políticas educacionais dos municípios da Região Fronteira Noroeste/RS para a construção de escolas inclusivas. A metodologia utilizada possui abordagem quanti-qualitativa com a aplicação de entrevistas e de questionários com questões abertas e fechadas. Os dados são analisados comparativamente em um primeiro momento, e na sequência constituem-se duas categorias de análise, identificadas no processo de construção da política de Educação Especial de um município: a) o processo de formação dos professores; e b) as ações e estratégias do Sistema Municipal de Ensino para a efetivação das condições necessárias ao processo de inclusão escolar. Os resultados da pesquisa revelam poucos avanços nas políticas de inclusão escolar nos municípios dessa região. Dos 11 municípios pesquisados, somente 5 atendem à totalidade da demanda da Educação Especial em suas escolas comuns, entretanto os resultados obtidos em um dos municípios pesquisados indicam avanços significativos no estabelecimento da inclusão escolar em relação aos processos de formação continuada dos professores e às ações administrativas, normativas e pedagógicas no Sistema Municipal de Ensino.
\end{abstract}

Palavras-chave: Educação Especial. Educação inclusiva. Políticas de inclusão.

\section{DEVELOPMENTS OF NATIONAL SPECIAL EDUCATION POLICY IN PERSPECTIVE OF INCLUSIVE EDUCATION POLICIES IN LOCAL}

\begin{abstract}
This article aims to present the impact that the Special Education National Policy in Perspective of Inclusive Education/2008 is causing in the educational policies of the municipalities in the North West Frontier/RS region for building inclusive schools. The methodology has quantita-
\end{abstract}

${ }^{1}$ Mestre em Educação nas Ciências - Unijuí. Doutoranda em Educação - UFSM. Integrante do Grupo de Estudos e Pesquisas em Educação Especial e Inclusão - Gepe - UFSM. Docente da UFFS - campus Cerro Largo - RS. neuseterigo@gmail.com. 
tive and qualitative approach to the application of interviews and questionnaires with open and closed questions. The data are analyzed comparatively at first, and following constitute two analysis categories identified in the construction process of the special education policy of a municipality: a) the process of teacher training; and b) the actions and strategies of the Municipal System of Education for the realization of the conditions necessary for the process of school inclusion. The results of this research show little progress in school inclusion policies in the municipalities of this region. Of the eleven municipalities surveyed, only five meet all the special education demand in their regular schools. However, the results obtained in one of the municipalities surveyed demonstrate significant progress in the implementation of school inclusion in relation to continuous training processes for teachers and administrative proceedings, regulatory and teaching at the Municipal School System.

Keywords: Special education. Inclusive education. Inclusion policies. 
A presente pesquisa vincula-se à temática da Educação Especial e às políticas para a educação inclusiva, considerando-as como forças de efetivação do direito à educação, mediante a democratização do acesso e permanência na escola. Sabe-se que este é um debate que acompanha por longas datas a trajetória de municípios e Estados brasileiros orientados por uma agenda mundial em torno da educação para todos como um direito humano e social. Desta forma, a política educacional brasileira tem estabelecido conexões e adesões a um conjunto de movimentos, sintetizados em conferências internacionais, que se traduzem na Política Nacional da Educação Especial na Perspectiva da Educação Inclusiva/2008 (BRASIL, 2008).

Essa Política está desafiando e mobilizando os sistemas de ensino estaduais e/ou municipais a organizarem políticas locais que atendam às suas diretrizes. Assim, este artigo apresenta o resultado de uma pesquisa realizada em municípios da Região Fronteira Noroeste/RS, que procurou saber como estes estão conduzindo suas políticas municipais de Educação Especial na perspectiva da construção de escolas inclusivas, afinal estamos há vários anos sob novas orientações legais, políticas e pedagógicas decorrentes da Política Nacional da Educação Especial/2008.

\section{Metodologia}

O caminho metodológico desta pesquisa consistiu, num primeiro momento, no reconhecimento da realidade regional quanto à instituição da Política Nacional da Educação Especial na Perspectiva da Educação Inclusiva/2008 nos municípios que compõem a Região Fronteira Noroeste do Estado do Rio Grande do Sul, integrantes do Conselho Regional de Desenvolvimento (Corede). ${ }^{2}$ Para tanto, utilizamos como instrumento de pesquisa um questionário com perguntas

\footnotetext{
2 Os Conselhos Regionais de Desenvolvimento (Coredes) são associações civis, sem fins lucrativos, criados no Estado do Rio Grande do Sul pela Lei $n^{\circ} 10.283$, de 1994, e regulamentados pelo Decreto $\mathrm{n}^{\circ}$ 35.764, também de 1994. Entre os seus objetivos consta a "Formulação e execução de estratégias regionais, consolidando-as em planos estratégicos de desenvolvimento regional". O Rio Grande do Sul é composto por 21 Coredes distribuídos regionalmente.
} 
abertas e fechadas sobre a realidade de cada município quanto à organização da sua política de Educação Especial, questionando sobre: a distribuição das matrículas dos alunos que são público-alvo da Política Nacional; a existência de salas de recursos multifuncionais ${ }^{3}$ e seu funcionamento; a definição de diretrizes e ações administrativas, pedagógicas e financeiras para a inclusão e a existência de processos formativos aos professores. O referido questionário foi aplicado ao gestor do órgão municipal de ensino ou ao responsável pelo setor de Educação Especial. Para isso, esclarecemos os objetivos da pesquisa e encaminhamos o Termo de Consentimento Livre e Esclarecido, o qual foi assinado pelo representante da Secretaria Municipal de Educação, resguardando os princípios éticos da pesquisa.

A partir desse mapeamento regional, definimos um município referência para aprofundar a análise quanto à organização da sua política municipal, utilizando a análise de documentos elaborados pelo Sistema Municipal de Ensino e um questionário com questões abertas, aplicado no setor pedagógico da Secretaria Municipal de Educação, responsável pela condução da política municipal.

Nesse mesmo município escolhemos uma escola a ser pesquisada, considerando três critérios: maior número de alunos integrantes do público-alvo (crianças com deficiências, transtornos do desenvolvimento global e superdotação/altas habilidades) matriculados na escola; existência de sala de recursos multifuncionais em funcionamento e professor especializado em Educação Especial atuando na sala de recursos. Os dados coletados na escola foram obtidos mediante questionário aplicado a: 1 professora da equipe diretiva, 1 professora da sala de recursos multifuncionais e 1 professora de sala de aula comum, as quais denominaremos P1 (Professora 1), P2 (Professora 2) e P3 (Professora 3), respectivamente, ao serem citados seus depoimentos.

\footnotetext{
As salas de recursos multifuncionais são espaços destinados ao Atendimento Educacional Especializado (AEE) oferecido aos alunos com deficiências em turno oposto às aulas da turma do ensino regular em que estão matriculados. São salas equipadas com materiais pedagógicos e equipamentos destinados a complementar e/ou suplementar a formação do aluno por meio da disponibilização de serviços, recursos de acessibilidade e estratégias que eliminem as barreiras para sua plena participação na sociedade e desenvolvimento de sua aprendizagem.
} 


\section{O Contexto Regional e a Política Nacional de Educação Especial}

Com o objetivo de investigar como a Política Nacional da Educação Especial na Perspectiva da Educação Inclusiva/2008 está sendo operacionalizada nos sistemas de ensino municipais da Região Fronteira Noroeste/RS, faz-se necessário, primeiramente, situá-la geograficamente. Essa região é composta por 20 municípios, no entanto para a discussão dos dados coletados trabalhamos com 11 municípios, ${ }^{4}$ pelo fato de que somente esses fizeram a devolução dos questionários encaminhados.

Segundo documento da Secretaria Estadual de Educação Diagnóstico da Educação Básica (RIO GRANDE DO SUL, 2010), a Região Fronteira Noroeste possui aproximadamente 200 mil habitantes concentrados numa área de 4.689 $\mathrm{Km}^{2}$, apresentando uma taxa de analfabetismo de 4,47\%. $\mathrm{O}$ atendimento à Educação Infantil corresponde a 74\%; o Ensino Fundamental, de 6 a 14 anos, possui atendimento pleno; e o Ensino Médio, de 15 a 17 anos, possui 94,26\% dos jovens frequentando a escola. São dados que se justificam pela existência de aproximadamente 240 estabelecimentos de ensino pertencentes às redes municipal, estadual e federal que atendem em torno de 50 mil estudantes.

No conjunto dos municípios pesquisados são identificados em relação ao porte territorial dez municípios de pequeno porte e somente um de médio porte, considerando sua população:

Tabela 1 - População da Região Fronteira Noroeste/RS

\begin{tabular}{|l|c|c|c|c|c|c|c|c|c|c|c|}
\hline Município & M1 & M2 & M3 & M4 & M5 & M6 & M7 & M8 & M9 & M10 & M11 \\
\hline População & 7.045 & 4.301 & 6.535 & 18.348 & 5.413 & 14.378 & 5.898 & 8.557 & 68.587 & 1.852 & 23.726 \\
\hline
\end{tabular}

Fonte: Dados IBGE/ Censo 2010.

${ }_{4}$ Para a apresentação dos dados dos 11 municípios utilizaremos a seguinte denominação: M1, M2, M3, M4, M5, M6, M7, M8, M9, M10, M11. 
Esclarecemos que esse estudo considera somente a rede municipal de ensino e que os dados sistematizados estão relacionados à: população; matrículas gerais; matrículas dos alunos com deficiências nas salas de recursos multifuncionais e nas turmas regulares e a formação dos professores para atuar nas salas de recursos.

Constata-se que o número de escolas mantidas pelo poder público municipal acompanha, proporcionalmente, a classificação do município: os de pequeno porte possuem entre 2 e 8 escolas e atendem entre 104 e 1.910 alunos, e somente um município, por ser de médio porte, destaca-se dos demais, com 31 escolas e 4.794 alunos matriculados na rede municipal.

Dada a escala de diferenciação entre um e outro município, a pesquisa trouxe dados gerais informando que sete municípios apresentam entre $100 \mathrm{e}$ 500 matrículas, três com matrículas entre 1000 e 2000 e um com quase 5000 matrículas, conforme pode-se observar na Tabela a seguir:

Tabela 2 - Número de Escolas e Matrículas

\begin{tabular}{|c|c|c|c|c|c|c|c|c|c|c|c|}
\hline Município & M1 & M2 & M3 & M4 & M5 & M6 & M7 & M8 & M9 & M10 & M11 \\
\hline Escolas & 05 & 03 & 05 & 08 & 05 & 07 & 02 & 04 & 31 & 03 & 13 \\
\hline Matrículas & 431 & 330 & 535 & 1910 & 227 & 1315 & 265 & 391 & 4794 & 104 & 1488 \\
\hline
\end{tabular}

Fonte: Dados dos questionários. Elaborada pela autora, 2014.

Deste conjunto de dados iniciais, esse estudo toma como foco de descrição e análise a realidade que envolve as salas de recursos multifuncionais e o Atendimento Educacional Especializado (AEE) realizado por professores especializados em Educação Especial.

O AEE é um dos pilares que sustentam a Política Nacional da Educação Especial na Perspectiva da Educação Inclusiva, em vigência deste 2008, e está previsto na Resolução do Conselho Nacional de Educação no 4/2009, que Institui Diretrizes Operacionais para o AEE na Educação Básica, modalidade da Educação Especial. Outros dois pilares que podem ser identificados com semelhante importância são: a) o duplo cômputo dos alunos com deficiências para a contabilização dos repasses financeiros pelo Fundo de Manutenção e Desenvolvimento da Educação Básica e de Valorização dos Profissionais da 
Educação (Fundeb) aos municípios, o qual possibilita aos sistemas de ensino maiores investimentos para o atendimento das necessidades destes; e b) os programas de formação ofertados sob a coordenação do Ministério da Educação (MEC), a fim de qualificar equipes gestoras e especializar professores.

A relevância ao funcionamento das salas de recursos deve-se ao fato de que elas assumem um papel de suplementação e complementação pedagógica nos processos de inclusão escolar. Elas introduzem a Educação Especial nas escolas comuns para se associar à educação geral e não para substituí-la. São espaços privilegiados para desenvolver estratégias pedagógicas que possam potencializar as capacidades e as condições dos alunos com deficiências para se envolverem nos processos de ensino na sala de aula comum:

$\mathrm{O}$ atendimento educacional especializado tem como função identificar, elaborar e organizar recursos pedagógicos e de acessibilidade que eliminem as barreiras para a plena participação dos alunos, considerando suas necessidades específicas. As atividades desenvolvidas no atendimento educacional especializado diferenciam-se daquelas realizadas na sala de aula comum, não sendo substitutivas à escolarização (BRASIL, 2008, p. 10).

Por essa razão, o que se espera do AEE não é um trabalho de normalização do aluno com deficiências, mas uma oportunidade para que ele possa impulsionar seu desenvolvimento por meio de estratégias pedagógicas específicas, que lhe permitam investimentos nas condições das suas funções psicológicas superiores $^{5}$ (controle consciente do pensamento, atenção, memória, abstração, raciocínio dedutivo, etc.).

Esses trabalhos podem, seguramente, se utilizar dos estudos vigotskianos porque estes rompem com a histórica concepção de que as condições biológicas são absolutamente determinantes para o desenvolvimento do indivíduo. Segundo as pesquisas de Vigotski, as funções superiores - ações conscientes e processos

5 Segundo Vigotski (2007), no processo geral de desenvolvimento podemos distinguir duas linhas qualitativamente diferentes de desenvolvimento: os processos elementares, que são de origem biológica; e as funções psicológicas superiores, que são de origem sociocultural. 
voluntários - formam-se não na matriz biológica, mas na matriz social e cultural. Elas não são inatas e sim originárias das relações que os indivíduos estabelecem com a cultura no meio social (VIGOTSKI, 2011, p. 864).

Desta forma, a inclusão escolar impulsionada pela atual política nacional defende que as crianças com deficiências sejam matriculadas nas escolas comuns. Ela propõe, positivamente, retirar as crianças do isolamento ou do convívio privado com seus iguais (em classes especiais), para colocá-las diante da necessidade da vida social na diversidade (em salas de aula comuns). Não basta, entretanto, que elas estejam lá. Por isso, a política nacional soma duas possibilidades - sala do AEE e sala de aula comum - para que a criança com deficiência vivencie experiências culturais e sociais, seja em momentos individualizados ou coletivos de aprendizagem.

Beyer (2010) sugere para esse processo educativo que a Pedagogia a ser elaborada para o aluno com necessidades especiais deve levar em conta suas condições de desenvolvimento e de aprendizagem e estabelecer dois planos de ação: um de ordem terapêutica e outro de caráter pedagógico. Com isso, não se está sugerindo que o AEE desempenhe a função de "ensinar" conteúdos escolares aos alunos com deficiências, ou que esteja voltado para compensações terapêuticas e/ou reforços comportamentais, mas que promova atividades específicas capazes de melhorar suas condições para a aprendizagem.

Beyer também propõe que as práticas da educação especial voltem-se "justamente para a esfera onde menos se acredita que possam ocorrer, ou seja, nas funções mentais superiores" (2010, p. 104). É justamente nas funções superiores que se deve manter o foco de trabalho com alunos com deficiências, pois o "desenvolvimento incompleto dos processos superiores não está condicionado pelo defeito de modo primário senão secundário" (VIGOTSKI, 2011, p. 222). Acredita-se, então, que os processos mentais superiores das crianças com deficiência dependem do desenvolvimento cultural e social que ela produz na coletividade. Por isso, o trabalho que é feito com elas nas salas de recursos tem como objetivo, além de desenvolver, preparar suas condições para que na sala de aula comum, em companhia dos demais colegas, possa obter experiências sociais e culturais que desafiem suas possibilidades, excedendo-as. 
Historicamente as práticas da Educação Especial ocuparam-se do desenvolvimento comportamental em detrimento da capacidade de abstração possível de ser desenvolvida pelas crianças com deficiências. Os estudos de Vigotski, porém, trouxeram contribuições que foram redimensionando a Educação Especial, principalmente quando defende que "o desenvolvimento das funções psíquicas superiores é possível somente pelos caminhos do desenvolvimento cultural" (VIGOSTKI, 2011, p. 869). Nesse sentido, o AEE precisa levar em consideração que a deficiência não está condenada à natureza, ou seja, não está restrita a fatores biológicos que definem as funções superiores. É pelo desenvolvimento cultural que será "possível compensar a deficiência" porque se as limitações orgânicas não lhe permitem avançar, "abre-se caminhos sem limites para o desenvolvimento cultural" (VIGOSTKI, 2011, p. 869).

A sala de recursos multifuncionais pode ser um espaço para construir caminhos alternativos, que levarão os alunos com deficiências ao desenvolvimento cultural, pois de acordo com Vigotski (2011, p. 868), as "formas culturais de comportamento são o único caminho para a educação da criança anormal. Elas consistem na criação de caminhos indiretos de desenvolvimento onde este resulta impossível por caminhos diretos". São caminhos indiretos de desenvolvimento que podem levá-los a ampliar suas condições de aprendizagem na sala de aula comum, e também participar ativamente na sociedade, tal como acontece com as pessoas surdas ou cegas, pois

[...] o desenvolvimento natural do comportamento não se relaciona, necessariamente, com essa ou aquela função orgânica. A fala não está obrigatoriamente ligada ao aparelho fonador, ela pode ser realizada em outro sistema de signos, assim como a escrita pode ser transferida do caminho visual para o tátil (VIGOTSKI, 2011, p. 868).

Apesar, contudo, de o trabalho das salas de recursos ser fundamental para o processo de inclusão, nem todos os municípios pesquisados possuem salas funcionando para atender toda a demanda de alunos. Temos, então, a seguinte realidade dos municípios sobre a existência das salas de recursos e profissionais para atuar nesse espaço: 
Tabela 3 - Salas de Recursos Multifuncionais e Formação dos Professores

\begin{tabular}{|c|c|c|c|c|c|c|c|c|c|c|c|}
\hline & M1 & M2 & M3 & M4 & M5 & M6 & M7 & M8 & M9 & M10 & M11 \\
\hline $\begin{array}{c}\text { Salas em fun- } \\
\text { cionamento }\end{array}$ & 00 & 01 & 01 & 02 & 00 & 01 & 01 & 02 & 09 & 00 & 00 \\
\hline $\begin{array}{c}\text { Salas em } \\
\text { implantação }\end{array}$ & 00 & 02 & 00 & 00 & 00 & 00 & 00 & 00 & 00 & 00 & 04 \\
\hline $\begin{array}{c}\text { Prof. com } \\
\text { formação para } \\
\text { atuar no AEE }\end{array}$ & sim & parcial & $\operatorname{sim}$ & $\operatorname{sim}$ & não & $\operatorname{sim}$ & $\operatorname{sim}$ & $\operatorname{sim}$ & sim & não & parcial \\
\hline
\end{tabular}

Fonte: Dados dos questionários. Elaborada pela autora, 2014.

Um dado importante a ser destacado é o fato de que existem apenas dois municípios (M1 e M5) que ainda não dispõem de salas de recursos (Tabela 3) e, por esse motivo, possuem alunos sem AEE (ver Tabela 4), embora um deles (M1) possua professor com formação ${ }^{6}$ para atuar na sala de recursos multifuncionais. Os motivos dessa realidade podem estar entre o fato de o Ministério de Educação não ter ainda destinado a sala de recursos ou então, ao município não oferecer condições estruturais (espaço específico) para colocá-la em funcionamento, pois essa é uma exigência do MEC para o envio dos materiais que a compõem. Outros dois municípios (M10 e M11) não possuem salas em funcionamento (Tabela 3), porém os alunos recebem o AEE na rede estadual ou na Associação de Pais e Amigos dos Excepcionais (Apae) (Tabela 4).

É significativo também que os demais municípios possuam salas de recursos e todas estejam em funcionamento com previsão do aumento do número destas em 2 municípios (M2 e M11), nos quais encontram-se 6 salas (Tabela 3) em fase de instalação. Não basta, no entanto, que as escolas estejam equipadas com as salas de recursos. É necessário que elas passem também por processos de discussão e reflexão sobre a inclusão, a fim de transformar suas práticas tradicionais de ensino sustentadas pelo paradigma da homogeneidade,

${ }_{6}$ A Resolução CNE 04/2009 em seu artigo 12 determina para atuação no AEE que o professor tenha formação inicial que o habilite para o exercício da docência e formação específica para a Educação Especial. 
por outras, que comecem a produzir uma outra cultura no espaço escolar. Essa nova cultura, necessariamente terá de ser inclusiva e considerar as diferenças como a essência dos seres humanos.

Na Tabela a seguir observa-se que seis municípios (M3, M6, M7, M9, M10 e M11) atendem a totalidade dos alunos no AEE que estão matriculados na sua rede de ensino; dois municípios (M1 e M5) possuem alunos com deficiências matriculados em suas escolas, porém como não existem salas de AEE instaladas e nem previsão para tanto, os alunos ficam sem atendimento especializado.

Tabela 4 - Alunos da Educação Especial e o AEE nas Escolas Comuns

\begin{tabular}{|c|c|c|c|c|c|c|c|c|c|c|c|}
\hline Município & M1 & M2 & M3 & M4 & M5 & M6 & M7 & M8 & M9 & M10 & M11 \\
\hline $\begin{array}{c}\text { Alunos da } \\
\text { Educação } \\
\text { Especial }\end{array}$ & 04 & $00^{*}$ & 05 & 35 & 03 & 01 & 03 & 29 & $\begin{array}{c}70 \\
35^{* * *}\end{array}$ & 03 & 25 \\
\hline $\begin{array}{c}\text { Alunos no } \\
\text { AEE }\end{array}$ & 00 & 00 & 05 & 24 & 00 & 01 & 03 & 24 & 70 & $03^{* * * *}$ & $25^{* *}$ \\
\hline $\begin{array}{c}\text { Alunos } \\
\text { sem AEE }\end{array}$ & 04 & 00 & 00 & $11^{* *}$ & 03 & 00 & 00 & 05 & 00 & 00 & 00 \\
\hline
\end{tabular}

Fonte: Dados dos questionários. Elaborada pela autora, 2014.

* Os alunos, público da educação especial estão na Apae (60 alunos).

** AEE oferecido na Apae municipal ou não são atendidos. *** Alunos em situação de diagnóstico.

****Alunos atendidos no AEE em outra rede de ensino.

A realidade dos municípios M4 e M8 apresenta uma situação que nos chama a atenção, pois existem salas de recursos e professores com formação (Tabela 3), mas alguns alunos não estão recebendo o AEE nas escolas comuns. Os motivos apresentados relatam que estes possuem deficiência física e, por isso, "não necessitam" do AEE ou então, o órgão municipal não informa o motivo.

O não atendimento pela sala de recursos aos alunos com deficiência física revela o quanto a inclusão escolar está relacionada ao campo cognitivo. Embora esse não atendimento possa ocorrer, todos os alunos público-alvo da Educação Especial devem usufruir desse apoio pedagógico. Não se justifica a sua exclusão, afinal a deficiência física os afeta emocionalmente e, como já foi dito anteriormente, o trabalho no AEE não se restringe a recuperar funções biológicas, mas a colocar o aluno em situações que ampliem suas experiências sociais e culturais e lhe possibilitem também vencer os preconceitos e a discriminação: 
A deficiência em si não é uma tragédia. É só o pretexto e o motivo para que surja a tragédia. [...] A deficiência orgânica em si é um fato biológico. Mas o educando não tem que operar tanto com esses fatos em si, quanto com suas consequências sociais. Quando estamos diante de uma criança cega como objeto da educação, devemos enfrentar, não tanto a cegueira, senão os conflitos que emergem a essa criança e o quanto isso se incorpora em sua vida (VIGOTSKI, 1997, p. 198-199).

A situação do M9 é interessante por apresentar um número expressivo de alunos matriculados (70) num contexto de quase 5.000 alunos e atender a todos, embora existam alguns em processo de diagnóstico. Logo após a Política Nacional da Educação Especial na Perspectiva da Educação Inclusiva, intensificou-se uma discussão em torno do entendimento de que os alunos somente seriam público do AEE mediante diagnósticos prescritos em laudo médico. Isso, no entanto, muda a partir da Nota Técnica 04/2014 (BRASIL, 2014), não mais condicionando a existência de laudo médico do aluno, porque isso "denotaria imposição de barreiras ao seu acesso aos sistemas de ensino, configurando-se em discriminação e cerceamento de direito" (BRASIL, 2014, p. 3). Assim, o diagnóstico passa a ser entendido como uma definição de "cunho estritamente educacional, a fim de que as estratégias pedagógicas e de acessibilidade possam ser adotadas pela escola favorecendo condições de participação e aprendizagem" (2014, p. 4). O apoio de profissionais da área clínica, entretanto, não está excluído, podendo a escola "articular-se com profissionais da área da saúde, tornando-se o laudo médico, neste caso, um documento anexo ao Plano de AEE" (p. 3). A partir do diagnóstico a elaboração e execução do plano de AEE é atribuída ao professor que atua na sala de recursos multifuncionais, "em articulação com os demais professores do ensino regular, com a participação das famílias e em interface com os demais serviços setoriais da saúde, da assistência social, entre outros, quando necessários” (p. 3).

Constatamos, ainda, que dos 11 municípios pesquisados, somente 5 (M4, M7, M8, M10, M11) atendem à totalidade dos alunos com deficiência nas escolas da rede municipal, oferecendo o AEE na própria escola. Dois municípios (M1, M5) não possuem salas de recursos (Tabela 3) e, por isso, existem alunos nas escolas comuns sem AEE e outros estão na escola especial existente no município, 
mas mantida pela Associação de Pais e Amigos dos Excepcionais (Apae). Um município (M2) não possui nenhum aluno na escola comum, estando todos na escola especial. Outros três municípios (M3, M6 e M9) atendem parcialmente, no entanto alguns permanecem nos espaços especiais e outros na escola comum.

As dificuldades que os municípios enfrentam para a organização da Política Nacional de Educação Especial na Perspectiva da Educação Inclusiva são de ordem administrativa, financeira e pedagógica. Para que ela se torne realidade e chegue até as escolas, são necessárias tomadas de decisão e investimentos pelo poder público (estadual ou municipal) para instalar as salas de recursos e dar o suporte de formação pedagógica necessário às escolas, além de outras questões estruturais. Talvez, no entanto, as questões administrativas e financeiras sejam ainda mais fáceis de serem organizadas do que as questões político-pedagógicas, pois estas demandam maiores esforços e dependem do engajamento político e ético de todos. Além disso, faz-se necessária a existência de processos formativos aos professores para que sua prática pedagógica esteja fundamentada tanto em saberes pedagógicos quanto em saberes específicos da área de Educação Especial.

\section{A Política Municipal de Inclusão e seus Desdobramentos na Escola}

A inclusão das crianças e adolescentes com deficiências nas escolas comuns não é uma proposta tão facilmente colocada em prática pelos órgãos municipais de educação e pelas escolas. Assim como todas as políticas públicas pensadas em âmbito nacional dependem da ação localizada dos agentes do poder público, nas instâncias estaduais e municipais, também a Política Nacional de Educação Especial na Perspectiva da Educação Inclusiva desdobra-se em políticas municipais que imprimem um conjunto de ações e estratégias para fortalecer as iniciativas inclusivas das escolas.

Há um conjunto de iniciativas e ações necessárias para construir condições favoráveis para que as crianças sejam matriculadas nas escolas e possam viver um processo de inclusão, o qual não depende delas, mas de todo um con- 
texto que vai além da matrícula e do atendimento educacional especializado. Essas condições, inicialmente, são da própria escola e suas estruturas, sejam elas arquitetônicas e/ou pedagógicas, porém serão muito mais eficazes se estiverem articuladas e forem decorrentes das políticas do órgão municipal de educação.

Por isso, após a análise da realidade regional sobre os processos de inclusão nos 11 municípios pesquisados, selecionou-se 1 deles para analisar junto a Secretaria Municipal de Educação suas ações e estratégias para instituir a Política Nacional da Educação Especial na Perspectiva da Educação Inclusiva. As razões para esta escolha deve-se ao fato de este apresentar maior número de escolas e alunos com deficiências matriculados nas escolas comuns. Esclarecemos que a partir dessa análise municipal foi escolhida uma escola pertencente a esse mesmo município para também analisar suas ações e estratégias no processo de inclusão no contexto escolar.

Mediante a entrevista realizada com a pessoa responsável pela Educação Especial na Secretaria Municipal de Educação, foi possível perceber que estava em andamento a construção de uma política municipal de Educação Especial, em decorrência de normativas nacionais. Dessa maneira, evidenciava-se que as políticas nacionais estavam provocando desdobramentos em ações municipais e escolares, como foi possível acompanhar na análise da realidade escolar.

Nesse segundo momento da pesquisa destaca-se a análise de duas ações significativas para a construção da política municipal de Educação Especial: a) a formação dos professores; e b) as ações estruturantes do sistema de ensino.

Quanto ao primeiro aspecto de análise - a formação dos professores - pode-se afirmar que este tem sido o maior desafio para efetivar processos inclusivos, porque frequentemente ouvimos o argumento de que as escolas e os professores não estão preparados para promover a inclusão em suas salas de aula comuns:

[...] atualmente os professores se deparam com esses alunos e sentem-se inseguros, despreparados. [...] na sala de aula você é sozinha e se depara com um grande desafio. Esta tarefa educativa é provavelmente a experiência mais comovente e radical que o professor pode ter $(\mathrm{P} 3,2014)$. 
Esse tem sido um limitador expressivo para a concretização do processo de inclusão nas escolas comuns. Os docentes, em sua maioria, não possuem conhecimentos específicos relacionados à Educação Especial, devido às políticas e às diretrizes nacionais de formação de professores, que historicamente orientaram os cursos de Licenciatura desconsiderando essa área de conhecimento pedagógico. Somente a partir de 2001 diretrizes curriculares nacionais ${ }^{7}$ fazem menção à necessidade da formação dos professores em cursos de Licenciatura contemplar estudos na área da Educação Especial.

O argumento de que "não estamos preparados" para trabalhar com alunos com deficiências constitui posturas resistentes em relação ao processo de inclusão. De certa forma, é uma realidade compreensível e justificável, porém não necessariamente aceitável e definitiva. É um contexto que pode ser alterado, a fim de transformar as situações de exclusão e de negação do direito à educação às pessoas com deficiências. Podemos compreender que os professores têm o direito de dizer que não sabem, mas ao mesmo tempo têm o dever de saber, pois não se pode negar um direito que é subjetivo, garantido na Constituição Federal/88.

Mediante a justificativa dos professores de que "não estão preparados" para trabalhar com os "anormais" em suas salas de aula, Skliar (2006, p. 31) posiciona-se dizendo que "parece que ainda não existe um consenso sobre o que significa 'estar preparado' e, muito menos, acerca de como deveria se pensar a formação quanto às políticas de inclusão". De acordo com a sua crítica, temos dificuldade para pensar uma formação que envolva a todos e não só aos alunos com deficiências. Talvez o despreparo não seja somente em relação aos alunos com deficiência, mas à educação em geral.

\footnotetext{
7 As Diretrizes Curriculares Nacionais para a Formação de Professores da Educação Básica, em nível superior, curso de Licenciatura, de Graduação plena, aprovadas pelo Conselho Nacional de Educação, em 2001, apontam que os currículos de formação de professores devem atender a uma política de integração dos alunos com necessidades educacionais especiais nas classes comuns dos sistemas de ensino. Isso exige que a formação dos professores das diferentes etapas da Educação Básica inclua conhecimentos relativos à educação desses alunos (BRASIL, 2001, p. 26, grifos nossos).
} 
Certamente são necessários saberes específicos da Educação Especial de acordo com as especificidades que dão um contorno às deficiências para conduzir as práticas de inclusão. Não podemos, contudo, restringir a necessidade de formação dos professores aos saberes do campo da Psicologia, da Psicopedagogia ou até mesmo, da Medicina. Faz-se necessário que a Pedagogia assuma a centralidade dos processos inclusivos, pensando a Educação Especial a partir de uma educação geral que possa incluir a todos. Nesse sentido, é pertinente retomar a perspectiva de educação presente na Política Nacional de Educação Especial, de 2008, ao indicar que a Educação Especial se dê numa "perspectiva de educação inclusiva".

Nessa direção, rompe-se com o pensamento de que a inclusão escolar acontece pelo AEE e na sala de recursos multifuncionais, restrita a esse espaço e ao trabalho específico com o aluno que possui deficiência. Introduz-se, isto sim, um pensamento que propõe a inclusão como uma matriz curricular, delineando a escola desde a sua proposta pedagógica até as suas práticas em geral, não só àquelas com os alunos que possuem deficiências e suas famílias, mas com todos.

A "perspectiva de educação inclusiva" exige novas "diretrizes filosóficas e pedagógicas na Educação e na política de formação de professores" (MIRANDA, 2011, p. 127) para que os processos educativos se afastem do binarismo normal-anormal, ao qual a escola se estruturou e separou os sujeitos de acordo com um padrão de normalidade. Aos ditos "normais" uma escola comum e uma educação geral, aos considerados “anormais", uma escola e uma educação especiais.

Afastar-se desse binarismo significa também revermos as noções de inclusão e exclusão, pois elas não são estados fixos aos quais os sujeitos poderiam se submeter plenamente. Podemos estar incluídos e excluídos ao mesmo tempo, ou então incluídos em algum ambiente e excluídos em outro. Por isso, a perspectiva é de inclusão, mas ela não se dá de forma absoluta. Lunardi (2000) explica que isso decorre de jogos de poder em que, dependendo da situação, da localização e da sua representação, alguns são enquadrados e outros não. 
A perspectiva inclusiva provoca as escolas a pensarem que a inclusão não está direcionada somente ao aluno com deficiência, mas a reconhecerem a diversidade dos sujeitos que fazem parte da comunidade educativa e dos seus modos de vida. Por isso, como esclarece Dorziat (2011, p. 155), "o direito de todos à Educação não deveria significar a mesma Educação para todos", mas a possibilidade de romper com a Pedagogia que possui noções de identidade única, de modelo de ensino e de modelo de aluno.

É no encontro com o outro, que sempre é diferente, que a educação vai produzindo diferentes relações entre os sujeitos. E a inclusão escolar, ao aproximar sujeitos que possuem deficiências daqueles que não as possuem, problematiza nossa convivência com o outro. Pode-se corroborar essa premissa no depoimento de uma das professoras: “[...] acredito que podemos beneficiar a aprendizagem de todos/as, inclusive potencializando a capacidade de ampliação do campo mental dos alunos que não apresentam necessidades educacionais especiais [...]” (P2, 2014).

Nesse sentido, a formação de professores para a inclusão escolar não pode restringir-se às especificidades das deficiências, mas refletir sobre as noções de "educação inclusiva", "inclusão", "exclusão”, "normal", "anormal”, "educação geral" e "educação especial". Isso tudo não se obtém com cursos de curta duração ou simplesmente algumas horas de estudo ou debates, e sim mediante estudos articulados com as práticas escolares.

Observa-se que o município em destaque desenvolve uma proposta de formação sistemática com encontros mensais com uma metodologia que se desdobra nas escolas sob a coordenação das professoras que atuam no AEE. Nos encontros mensais participam as equipes diretivas, as professoras do AEE de todas as escolas e equipe da Secretaria de Educação, e nos encontros escolares são envolvidos todos os professores e a equipe diretiva. Essa metodologia proporciona autonomia para cada escola fazer a sua caminhada, e ao mesmo tempo manter a formação vinculada aos problemas vivenciados na escola e às práticas pedagógicas dos professores. Também demonstra um trabalho articulado entre a Secretaria de Educação e as escolas, com responsabilidades compartilhadas, corroborando a manifestação da professora: 
Acredito na construção de um processo educacional incluso pautado no planejamento gradativo, contínuo, responsável, considerando as necessidades presentes em nossa escola, pois só será possível construirmos novas práticas pedagógicas reconhecendo as capacidades dos alunos, respeitando suas diferenças e proporcionando condições de aprendizagem a todos/as (P1, 2014).

Nesse processo de formação também há espaço aberto às reflexões pertinentes aos anseios, aos medos e às expectativas dos professores. Esses são discutidos e revertidos em afirmação pessoal e/ou profissional e em possibilidades de intervenções pedagógicas e/ou curriculares. Espera-se, desta forma, obter uma formação continuada que

[...] não se construa por acumulação (de cursos, de conhecimentos ou técnicas), mas, sim por meio de um trabalho de reflexividade crítica sobre as práticas de (re)construção permanente de uma identidade pessoal. Por isso é tão importante investir na pessoa e dar um estatuto ao saber da experiência (NÓVOA, 1992, p. 25).

Schön (1992) também considera que o pensamento crítico sobre sua própria ação leva o professor a reelaborar novas estratégias, porque a formação dos professores é um processo que se dá no desenvolvimento da ação pedagógica, na prática da sala de aula, que, acompanhada pela reflexão, constitui-se em saberes, em conhecimentos que potencializam as práticas. Percebe-se essa busca no depoimento da professora que trabalha com um aluno autista na sala de aula comum:

Não há uma receita para resolver as dificuldades, mas aos poucos você vai conhecendo o aluno e procura descobrir seus interesses, possibilidades, enfim, conhecê-lo [...] e a partir dai escolher os materiais adequados, sempre priorizando a comunicação e a socialização, mesmo sabendo que para o autista o relacionamento com outras pessoas costuma não despertar interesse (P3).

Nesse sentido, a formação continuada dos professores é um processo inevitável a ser pensado pelos sistemas de ensino para modificar situações relacionadas a um "não saber", que pode ser em relação à educação geral e 
não somente à Educação Especial. Por isso, é na formação dos professores que reside um enorme esforço a ser empreendido para alterar as formas pelas quais temos pensado o sujeito, a escola e suas práticas pedagógicas de ensino, nas quais encontramos concepções que são empecilhos à inclusão por estarem sustentadas no paradigma da homogeneidade, ignorando as diferenças.

Dorziat esclarece que:

A indefinição do perfil docente para a inclusão é, nesse sentido, decorrente da dificuldade de uma abordagem sistêmica sobre formação de professores, que envolva todos os alunos, e não apenas os alunos com deficiência. Essa abordagem pode permitir ao professor desenvolver a capacidade de compreender e praticar o acolhimento às diferenças, com uma postura de abertura às singularidades humanas na experiência prática, a fim de poder planejar aulas que levem em conta tais informações (2011, p. 150).

O segundo aspecto da nossa análise - as ações e estratégias do sistema de ensino - nos permitiram observar que as ações político-administrativas formalizadas pela Secretaria Municipal de Educação e as normatizações do Conselho Municipal de Educação (CME) foram orientadoras às ações da escola para organizar a sua política escolar de inclusão. São ações e estratégias que vão constituindo uma política municipal e tornam-se fundamentais para que as propostas pedagógicas das escolas possam realmente se efetivar com o apoio e responsabilidade administrativa da Secretaria de Educação.

São três resoluções emitidas pelo Conselho Municipal de Educação que normatizam a Educação Especial no sistema municipal de ensino: a) Resolução CME 03/2011, que regulamenta o AEE nas escolas de Ensino Fundamental na rede municipal; b) Resolução CME 04/2011, que dispõe sobre a constituição de turmas no Ensino Fundamental e das turmas de alunos no AEE; e c) Resolução CME 05/2012, que estabelece as diretrizes para a Educação Especial no sistema municipal de ensino.

A primeira Resolução define com mais especificidade ações relacionadas ao AEE esclarecendo suas funções e sua condição não substitutiva ao ensino regular e sobre a necessária formação dos professores para atuar na sala de re- 
cursos e as suas atribuições. No questionário respondido pela professora que atua na sala de AEE constata-se que a escola segue o que está previsto na legislação nacional e municipal sobre o estabelecimento de "articulação com os professores da sala de aula comum e com os demais profissionais da escola, visando à disponibilização dos serviços, e recursos pedagógicos (...)" (CME, 2011, p. 2), porque sua formação atende aos requisitos legais e ainda, a escola dispõe de

[...] ]uma sala equipada, com materiais pedagógicos específicos; liberdade de interação com os professores da sala comum e com a equipe diretiva; condições físicas e funcionais para desenvolver o trabalho [...] com base no diálogo e construção de estratégias com todas as instâncias que envolvem o processo educativo e multidisciplinar ( $\mathrm{P} 2,2014)$.

Essa normatização estabelece uma atribuição estratégica ao professor que atua na sala do AEE quando o coloca como o articulador do processo de inclusão no interior da escola, mobilizando os colegas e estabelecendo um trabalho pedagógico integrado com os professores das salas de aula comum. Sem isso, corre-se o risco de mais uma vez a Educação Especial se isolar e se desvincular da proposta da escola, ficando restrita ao "atendimento" dos alunos que possuem deficiências, reforçando uma perspectiva clínica.

A segunda Resolução CME 04/2011 trata sobre a constituição das turmas no Ensino Fundamental e das turmas com alunos no AEE, na sala de recursos, o que dá ao professor que atua na sala de aula comum a garantia de que sua turma terá redução no número de alunos e também não contará com diversos alunos com diferentes deficiências. Assim, haverá melhores condições para o desenvolvimento de um trabalho próximo de cada um dos aprendizes. Ao trabalhar com alunos da Educação Especial na sala de aula comum é preciso considerar que "é um jeito diferente de aprender e um jeito diferente de ensinar" (P 2, 2014).

Somada a uma sólida formação profissional para a inclusão escolar está a valorização e o respeito ao trabalho dos professores, mediante as condições necessárias para que possa desenvolver uma prática pedagógica qualificada. Essa qualificação depende de tempo para estudo e planejamento e também que sejam respeitados critérios para a inclusão dos alunos com deficiência nas turmas 
regulares, ou seja, faz-se necessário definir um número razoável de matrículas, a fim de proporcionar condições para que o professor possa dedicar atenção a todos os educandos. Nesse sentido Oliveira (2009), a partir de seus estudos, questiona o número elevado de alunos com diferentes tipos de deficiência em uma mesma turma regular e coloca em dúvida como o professor poderia dar conta dos processos de aprendizagem de todos os alunos.

A terceira Resolução CME 05/2012 estabelece as diretrizes para a Educação Especial no Sistema Municipal de Ensino. Ela esclarece quanto aos fins e meios para a oferta da Educação Especial nos currículos escolares; define e caracteriza os alunos que serão atendidos pela política municipal, entre outras questões. Quanto à formação dos professores, prevê a existência de "formação continuada e/ou capacitação de professores que atuam no atendimento educacional especializado e demais professores" (CME, 2012, p. 2). Nesse caso, observam-se pelo depoimento das professoras os efeitos dessas diretrizes nas ações tanto da Secretaria Municipal de Educação quanto da escola:

Na escola, a formação é realizada conforme calendário organizado pela coordenação da mesma. Enquanto que a responsabilidade em ministrá-las cabe às educadoras do AEE. Em relação à Secretaria Municipal de Educação os encontros acontecem mensalmente com temas pertinentes a Deficiências, Transtornos Globais do Desenvolvimento e Altas Habilidades no contexto da inclusão (P2, 2014).

Analisando o Plano de Carreira do Magistério Público Municipal, verifica-se que o poder Executivo municipal preocupou-se com a organização de uma política de Educação Especial ao prever no referido Plano cargos e funções relacionadas ao atendimento do público da Educação Especial. O Plano aprovado em 2012 é posterior ao surgimento da Política Nacional de Educação Especial na Perspectiva da Educação Inclusiva/2008, demonstrando os efeitos desta nas ações e estratégias político-administrativas do poder público municipal. O Plano contempla entre os cargos de docência, dois cargos e funções de profissionais que contribuem para compor o apoio pedagógico necessário às crianças com deficiências. São eles: o psicopedagogo e o educador especial, sendo este aquele que atuará nas salas de AEE. Para este último, suas funções relativas ao cargo 
consistem em identificar, elaborar, produzir e organizar serviços, recursos pedagógicos, de acessibilidade e estratégias, considerando as necessidades específicas dos alunos público-alvo da Educação Especial (PREFEITURA..., 2012).

Assim, vemos que a organização da política municipal de Educação Especial desse município, campo de nosso estudo, caminha para o fortalecimento da inclusão das crianças com deficiências nas escolas comuns, seguindo a política nacional. As ações e estratégias que foram instituídas e regulamentadas em leis e resoluções não são passageiras, e desta forma, são importantes estruturas para o funcionamento de uma política municipal. Essas ações contribuem para a formação de uma nova ordem em torno da Educação Especial, constituindo-se em uma política pública que segue um quadro normativo de ação e combina elementos de força pública e elementos de competência para produzir uma ordem local (MULLER; SUREL, 2010).

Bem sabemos, no entanto, que leis e normatizações não produzem a realidade por si só, são também necessárias mudanças no modo de pensar e de agir das pessoas, porque todas essas ações, assim como o AEE na escola, são apenas recursos "para auxiliar no processo de inclusão, haja vista que o compromisso é de toda a comunidade escolar e por extensão de toda a sociedade” (P2, 2014).

\section{Considerações Finais}

O processo de inclusão de alunos/as com deficiência no ensino regular (escolas e salas de aula comuns), na forma apresentada pela Política Nacional da Educação Especial na Perspectiva da Educação Inclusiva, traz consigo uma história de mudanças que traduz lutas sociais e políticas produzidas mundialmente, nas quais o Brasil tem se engajado de forma bastante consistente nos últimos anos. Por isso, processos para a construção de uma educação inclusiva estão em curso na sociedade brasileira. Podemos observá-los a partir de pesquisas como a que apresentamos aqui. Obviamente, contudo, não podemos esperar ou imaginar que a inclusão escolar se concretize como uma totalidade, ou seja, seria um equívoco imaginarmos que chegaremos a um estágio completo e perfeito 
de inclusão das pessoas com deficiências na escola comum. Estaremos permanentemente lutando para tornar a escola um espaço para todos e de maneira que sejam respeitadas as diferenças que ali se encontram.

Vemos muitos professores envolvidos e dispostos a tornar a escola um espaço social capaz de contribuir para a promoção de mudanças na sociedade, acreditando que pela sua capacidade de educar podem construir um outro mundo, com menos exclusões e mais inclusões. A experiência que se produz com o outro a partir da inclusão é uma possibilidade para que outras relações entre as pessoas possam se constituir; que as configurações tão consistentes entre a anormalidade e a normalidade, ou seja, entre o sujeito dito "anormal" e o "normal", possam ser questionadas e produzam reflexões que levem a uma nova ética da alteridade.

Freire (1998) nos ajuda a compreender que não basta constatarmos e justificarmos as dificuldades que temos em relação à inclusão das crianças com deficiências na escola como algo determinado e imutável, mas ele nos encoraja a nos tornarmos capazes de intervir positivamente nessa realidade. Freire insiste que "ninguém pode estar no mundo, com o mundo e com os outros de forma neutra", e complementa destacando que "não posso estar no mundo de luvas nas mãos constatando apenas" (FREIRE, 1998, p. 86). Por isso, em cada movimento inclusivo que as escolas ou sistemas municipais colocam em funcionamento, existe esperança, não de quem espera simplesmente, mas de quem vai transformando a esperança em ações concretas que afetam diretamente os sujeitos, garantindo-lhes mais direitos e mudando sua vida.

A luta pela inclusão das pessoas com deficiências na escola, no entanto, não está restrita somente aos espaços escolares, pois ela se apresenta na dimensão da garantia do direito à educação, como um direito humano que envolve a sociedade em geral. Construir escolas democráticas e inclusivas contribui com a construção de uma sociedade também democrática e mais igualitária, e inversamente o mesmo também acontece, pois uma sociedade democrática e igualitária contribui para que a escola também adote este caráter. Nesse sentido, mudar a escola, tornando-a mais inclusiva, é mudar a sociedade. 
A esperança que colocamos na tarefa educativa que ocorre nos espaços escolares entre professores e alunos alimenta-se pela crença de que a "educação sozinha não transforma a sociedade, sem ela tampouco a sociedade muda" (FREIRE, 2000, p. 67). Freire (2000) nos fortalece nessas crenças quando afirma que, se nossa opção é progressista, se estamos a favor da vida e não da morte, da equidade e não da injustiça, do direito e não do arbítrio, da convivência com o diferente e não da sua negação, não temos outro caminho senão viver plenamente a nossa opção. Encarná-la, diminuindo assim a distância entre o que dizemos e o que fazemos (FREIRE, 2000).

Nesse sentido, incluir exige a convicção de que a mudança é possível (FREIRE, 2011). O fato de a Política Nacional da Educação Especial na Perspectiva da Educação Inclusiva apresentar como obrigatoriedade a inclusão das pessoas com deficiência na escola regular, afastando-se da segregação e da integração destas em escolas ou classes especiais, pode representar algo novo na educação. Ao "invadir" a escola, instalando salas de recursos multifuncionais, oferecendo formação continuada aos professores e o duplo cômputo do aluno para o repasse dos recursos financeiros pelo Fundo de Manutenção e Desenvolvimento da Educação Básica e de Valorização dos Profissionais da Educação (Fundeb), está apresentando possibilidades concretas e responsáveis para a mudança. Sabemos, entretanto, que a mudança não ocorre por forças superiores, ela acontece quando faz parte dos sonhos e projetos coletivos. E essa decisão está nas mãos das comunidades escolares e dos órgãos gestores locais, mobilizadores para a concretização da Política Nacional.

Com o objetivo de analisar os impactos da Política Nacional de Educação Especial na Perspectiva da Educação Inclusiva na Região Fronteira Noroeste do Estado do Rio Grande do Sul, fizemos uma trajetória que percorreu a região (embora não tenha atingido a totalidade dos municípios) e nos detivemos a investigar com mais detalhes a realidade de um município que vem demonstrando avanços significativos na elaboração de uma política municipal de Educação Especial.

Nesse contexto regional constatou-se diferentes efeitos da Política Nacional de Educação Especial. De maneira geral há muito por fazer, embora um município (M9) tenha se destacado, porque foram empreendidas importantes ações administrativas e pedagógicas para proporcionar condições às escolas para 
construírem também sua política de inclusão (uma "política escolar"). Isso nos leva a entender que uma política pública nacional não pode ser considerada simplesmente em uma relação sequencial. Seu desdobramento em "ordens locais" depende dos atores políticos, indivíduos ou grupos, que se envolvem com sua construção (MULLER; SUREL, 2010). Depende da tradução que é feita dela e do sentido a ela atribuído pelos sujeitos políticos e pela população envolvida.

Vimos nessa pesquisa que as ações de ordem administrativa e legal efetivaram os objetivos da Secretaria Municipal de Educação deste município, demonstrando seu comprometimento com a política nacional de inclusão escolar e influenciaram decisivamente as práticas pedagógicas da escola pesquisada e seus professores.

Da mesma forma, as ações pedagógicas indicaram o caminho para a formação continuada articulada entre a Secretaria Municipal de Educação e as escolas, proporcionando autonomia a esta escola para organizar seu processo de formação pedagógica. Com isso, a escola está compreendendo que o processo de inclusão deve ser acompanhado por propostas de formação político-pedagógica com toda a comunidade escolar, pois "só será possível construirmos novas práticas pedagógicas reconhecendo as capacidades dos/as alunos/as, respeitando suas diferenças e proporcionando condições de aprendizagem significativa a todos/as” (P1, 2014).

Nesse sentido, conclui-se afirmando que dotar os sistemas municipais de ensino com ações estratégicas administrativas e pedagógicas é fortalecer a instituição da Política Nacional de Educação Especial na Perspectiva da Educação Inclusiva. Essas ações cumprem o papel de institucionalizar uma política municipal de inclusão, como efeito da política nacional.

\section{Referências}

BRASIL. Parecer CNE 9/2001, de 8 de maio de 2001. Diretrizes Curriculares Nacionais para a Formação de Professores da Educação Básica, em nível superior, curso de Licenciatura, de Graduação plena. Disponível em: <http://portal.mec.gov.br/cne/arquivos/ pdf/009.pdf>. Acesso em: 10 mar. 2016. 
BRASIL. Ministério da Educação. Secretaria da Educação Especial. Inclusão: Revista da Secretaria da Educação Especial, v. 1, n. 1, out. 2008.

. Resolução $C N E n^{o} 4$, de 2 de outubro de 2009. Diretrizes Operacionais para o AEE. Disponível em: <http://portal.mec.gov.br/dmdocuments/rceb004_09.pdf >.Acesso em: 10 mar. 2014.

. Nota Técnica $n^{\circ} 4$, de 23 de janeiro de 2014. Orientação quanto a documentos comprobatórios de alunos com deficiências, transtornos globais do desenvolvimento e altas habilidades e superdotação no Censo Escolar. Disponível em: <http://portal.mec. gov.br/index.php?option=com_content $\&$ view=article $\&$ id=16761\&Itemid=1123>. Acesso em: 10 nov. 2014.

BEYER, Hugo O. Inclusão e avaliação na escola de alunos com necessidades educacionais especiais. 3. ed. Porto Alegre: Mediação, 2010.

CONSELHO MUNICIPAL DE EDUCAÇÃO/CME. Resolução $C M E n^{o} 3$, de 12 de julho de 2011. Regulamenta o Atendimento Educacional Especializado - AEE - nas escolas da rede municipal. 2011a. Disponível em: <http://cme.santarosa.rs.gov.br/>. Acesso em: 14 mar. 2015.

. Resolução $C M E n^{\circ} 4$, de 13 de setembro de 2011. Dispõe sobre a constituição das turmas no Ensino Fundamental e das turmas com alunos público-alvo do AEE, nas escolas do Sistema Municipal de Ensino de Santa Rosa. 2011b. Disponível em: <http:// cme.santarosa.rs.gov.br/>. Acesso em: 13 mar. 2015.

. Resolução $\mathrm{CME}^{\circ}$ 5, de 13 de novembro de 2012. Estabelece diretrizes para a educação especial no Sistema Municipal de Ensino de Santa Rosa. Disponível em: http:// cme.santarosa.rs.gov.br/ Acesso em: 14 de março de 2015.

DORZIAT, Ana. A formação de professores e a educação inclusiva: desafios contemporâneos. In: CAIADO, Katia R. M.; JESUS, Denise M. de; BAPTISTA, Claudio R. (Org.). Professores e educação especial. Porto Alegre: Mediação, 2011. Vol. 2.

INSTITUTO BRASILEIRO DE GEOGRAFIA E ESTATÍSTICA (IBGE). Censo Demográfico/2010. Disponível em: <http://www.censo2010.ibge.gov.br/sinopse/index. php?uf $=43 \&$ dados=0 $>$. Acesso em: 12 nov. 2014.

FREIRE, Paulo. Pedagogia da autonomia: saberes necessários à prática educativa. 8 . ed. São Paulo: Paz e Terra, 1998.

. Pedagogia da indignação: cartas pedagógicas e outros escritos. São Paulo: Unesp, 2000.

. Pedagogia da autonomia: saberes necessários à prática educativa. 15. ed. São Paulo: Paz e Terra, 2011. 
LUNARDI, Marcia L. Inclusão/exclusão: duas faces da mesma moeda. Cadernos de Educação Especial. Santa Maria, v. 2, n. 18, p. 27-36, 2000.

MIRANDA, Theresinha G. Desafios da formação: dialogando com pesquisas. In: CAIADO, Katia R. M.; JESUS, Denise M. de; BAPTISTA, Claudio R. (Org.). Professores e educação especial. Porto Alegre: Mediação, 2011. Vol. 2.

MULLER, Pierre; SUREL, Yves. A análise das políticas públicas. 2. ed. Pelotas: Educat, 2010.

NÓVOA, Antônio. Os professores e sua formação. Lisboa: Dom Quixote, 1992.

OLIVEIRA, Ivanilde A. de. Política de educação inclusiva nas escolas: trajetórias de conflitos. In: JESUS, Denise M. et al. (Org.). Inclusão, práticas pedagógicas e trajetórias de pesquisa. 2. ed. Porto Alegre: Mediação, 2009.

PREFEITURA MUNICIPAL DE SANTA ROSA/PMSR. Lei $n^{\circ} 72$, de 3 de janeiro de 2012. Estabelece o Plano de Carreira do Magistério Público do Município de Santa Rosa. Institui o respectivo quadro de cargos e funções e dá outras providências. Disponível em: $<$ http://downloads.santarosa.rs.gov.br/downloads/leis/lc72_03_01_2012.pdf>. Acesso em: 12 mar. 2015.

RIO GRANDE DO SUL. Secretaria da Educação do RS. Departamento de Planejamento. Diagnóstico da Educação Básica com Ênfase no Ensino Médio, 2010. Disponível em: $<$ http://www.educacao.rs.gov.br/dados/diagnostico_relatorio_final_2010.pdf>. Acesso em: 15 mar. 2015.

SCHÖN, Donald A. Formar professores como profissionais reflexivos. In: NÓVOA, Antônio. Os professores e sua formação. Lisboa: Dom Quixote, 1992.

SKLIAR, Carlos. A invenção e a exclusão da alteridade "deficiente" a partir dos significados da normalidade. Educação e Realidade, n. 24 (1), jul./dez., p. 15-32, 1999.

A “inclusão" que é nossa e a diferença que é do "outro". In: RODRIGUES, David (org). Inclusão e educação: doze olhares sobre a educação inclusiva. São Paulo: Summus, 2006.

VIGOTSKI, Lev S. A defectologia e os estudos do desenvolvimento e da educação da criança. Revista Educação e Pesquisa, São Paulo, v. 37, n. 4, p. 861-870, dez. 2011.

. A formação social da mente: o desenvolvimento dos processos psicológicos superiores. 7. ed. São Paulo: Martins Fontes, 2007.

VYGOSTKY. Lev S. Obras escogidas: fundamentos da defectologia. Tomo V, Madrid: Visor, 1997.

Recebido em: 25/5/2016

Aceito em: 4/11/2016 